\title{
Do we need to measure vitamin $B / 2$ and magnesium in morbidly obese patients with type 2 diabetes mellitus?
}

This article was published in the following Dove Press journal:

Diabetes, Metabolic Syndrome and Obesity:Targets and Therapy 2 May 2017

Number of times this article has been viewed

\author{
Anna Wåhlén' \\ Arvo Haenni ${ }^{2,3}$ \\ Hans-Erik Johansson ${ }^{1-3}$ \\ 'Östervåla Primary Health Care \\ Centre, Östervåla, ${ }^{2}$ Department of \\ Public Health and Caring Sciences/ \\ Geriatrics, Uppsala University, \\ Uppsala, ${ }^{3}$ Skönvikt, Outpatient Clinic \\ of Obesity Care, Säter, Sweden
}

Objective: We aimed to investigate the prevalence of B12 deficiency in metformin-treated, morbidly obese, type 2 diabetes mellitus (T2DM) patients, compared to morbidly obese controls, as well as to evaluate the magnesium status.

Design: Retrospective cross-sectional analysis of plasma vitamin B12, plasma magnesium, glucometabolic status and clinical measurements in all consecutive morbidly obese patients was conducted during 1 year.

Setting: Outpatient Clinic of Obesity Care.

Subjects: One hundred forty-seven patients were evaluated: 107 morbidly obese controls and 40 metformin-treated, morbidly obese patients with T2DM.

Main outcome measures: Circulating plasma concentrations of vitamin B12 (cobalamin), magnesium, clinical measurements and metformin medication.

Results: There were differences between the two groups regarding age, sagittal diameter, glucose parameters and magnesium concentrations. Longer diabetes duration was associated with lower magnesium. Metformin-treated T2DM patients had lower magnesium $(0.76 \pm 0.07 \mathrm{mmol} / \mathrm{L})$ than controls $(0.82 \pm 0.07 \mathrm{mmol} / \mathrm{L})$. A subgroup analysis of 26 non-metformin-treated T2DM patients showed a normal magnesium concentration compared to controls, that is, $0.81 \pm 0.06 \mathrm{mmol} / \mathrm{L}$. We found no statistical difference in B12 concentrations between the two groups.

Conclusion: To fully benefit from metformin medication, routine testing of B12 as well as magnesium in metformin-treated, morbidly obese patients should be performed, with consideration of substitution to avoid low levels.

Keywords: metformin medication, vitamin B12, magnesium, type 2 diabetes mellitus, morbidly obese

\section{Introduction}

Metformin, a widely used insulin-sensitizing drug, is a first-line treatment for type 2 diabetes mellitus (T2DM). It is cost-effective, without the risk of hypoglycemia, and a UK prospective study has shown that metformin reduces cardiovascular diseases (CVDs) and death. ${ }^{1}$ Long-term use of metformin, especially at a high dose, has been associated with subsequent reduction in vitamin B12 plasma concentrations. Metformin interferes with calcium-dependent uptake of B12 and intrinsic factor and may cause B12 deficiency. Identifying B12 deficiency is clinically relevant, since several conditions may ultimately result in macrocytic anemia, neuropathy, cognitive dysfunction and mental changes. ${ }^{2}$ Previous studies have reported a prevalence of B12 deficiency of $\sim 10 \%-20 \%$ in T2DM patients undergoing metformin treatment and less than half of this prevalence in the general population. ${ }^{3,4}$ Our impression from daily work, treating
Correspondence: Hans-Erik Johansson Department of Public Health and Caring Sciences/Geriatrics, Uppsala University, Uppsala Science Park, 75I85 Uppsala, Sweden

Tel +46 I $86 I I 0000$

Fax +46 I 86II 7976

Email hans-erik.johansson@pubcare.uu.se 
T2DM patients and medically evaluating morbidly obese patients, is that B12 deficiency is not as common, especially not with clinical manifestations. However, B12 deficiency remains controversial, since there is no consensus on the clinical definition and a lack of recommendations in clinical guidelines regarding metformin treatment and detection of B12 deficiency.

Magnesium is a cofactor involved in many enzymatic processes as well as in glucose metabolism. Diabetes is associated with low magnesium, and hypomagnesemia is associated with insulin resistance, inflammation and increased risk for CVD. ${ }^{5}$ Hypomagnesemia could be a consequence of increased renal magnesium and glucose excretion due to hyperglycemia. ${ }^{6}$ Haglin et al have previously reported a significant increase in all-cause mortality when low magnesium was added to traditional risk factors in patients with diabetes. ${ }^{7}$ Metformin medication has been associated with possibly lower plasma magnesium concentrations and renal magnesium excretion, ${ }^{5}$ which theoretically jeopardize the positive cardiovascular effects of metformin.

We aimed to investigate the prevalence of B12 deficiency in metformin-treated T2DM morbidly obese patients compared to obese controls, as well as to evaluate the magnesium status.

\section{Patients and methods}

This was a cross-sectional retrospective study of 1 year outcome of plasma magnesium, B12 and glucometabolic status in all consecutive patients who later underwent bariatric surgery. Data and medication were collected from the patients' medical records. One hundred forty-seven patients were included, consisting of 107 morbidly obese ( 31 male/76 female) controls with a mean weight $126.2 \pm 20.0 \mathrm{~kg}$, body mass index $43.5 \pm 5.9 \mathrm{~kg} / \mathrm{m}^{2}$, sagittal diameter $31.9 \pm 3.7 \mathrm{~cm}$, age $43.2 \pm 11.5$ years, glycated hemoglobin $38.1 \pm 4.4 \mathrm{mmol} / \mathrm{mol}$ and fasting plasma (f-P) glucose 5.9 $\pm 0.6 \mathrm{mmol} / \mathrm{L}$ and 40 (19 male/21 female) metformin-treated, morbidly obese patients with T2DM with a mean weight $131.8 \pm 21.0 \mathrm{~kg}$, body mass index $44.3 \pm 5.7 \mathrm{~kg} / \mathrm{m}^{2}$, sagittal diameter $33.9 \pm 3.7 \mathrm{~cm}$, age $51.1 \pm 8.8$ years, glycated hemoglobin $65.1 \pm 17.0 \mathrm{mmol} / \mathrm{mol}$ and $\mathrm{f}-\mathrm{P}$ glucose $10.7 \pm 3.3 \mathrm{mmol} / \mathrm{L}$. Mean diabetes duration was $6.4 \pm 5.6$ years, and mean metformin dose was $1848 \pm 896 \mathrm{mg}$. Clinical characteristics are shown in Table 1 . None of the recruited patients were taking B12 or magnesium supplements. Routine chemical tests were all carried out at the Department of Clinical Chemistry at the Central Hospital, Falun. Plasma magnesium was measured by spectrophotometric determination with xylidyl blue (ADVIA Chemistry XPT System,
Table I Characteristics and results for obese T2DM patients treated with metformin and obese controls

\begin{tabular}{|c|c|c|c|}
\hline & $\begin{array}{l}\text { Obese T2DM } \\
\text { patients on } \\
\text { metformin }\end{array}$ & $\begin{array}{l}\text { Obese } \\
\text { controls }\end{array}$ & $\begin{array}{l}p \text {-Value } \\
\text { of the } \\
\text { difference }\end{array}$ \\
\hline Number of patients & $40(19 \mathrm{M} / 2 \mathrm{I} \mathrm{F})$ & 107 (3I M/76 F) & \\
\hline Age (years) & $51.1 \pm 8.8$ & $43.2 \pm 11.5$ & $<0.001$ \\
\hline Weight (kg) & $131.8 \pm 21.0$ & $126.2 \pm 20.0$ & 0.137 (ns) \\
\hline BMI $\left(\mathrm{kg} / \mathrm{m}^{2}\right)$ & $44.3 \pm 5.7$ & $43.5 \pm 5.9$ & $0.46 \mathrm{I}$ (ns) \\
\hline Sagittal diameter & $33.9 \pm 3.7$ & $31.9 \pm 3.7$ & 0.004 \\
\hline f-P glucose & $10.7 \pm 3.3$ & $5.9 \pm 0.6$ & $<0.001$ \\
\hline $\mathrm{HbA}_{\mathrm{lc}}(\mathrm{mmol} / \mathrm{mol})$ & $65.1 \pm 17.0$ & $38.1 \pm 4.4$ & $<0.001$ \\
\hline $\begin{array}{l}\text { Diabetes duration } \\
\text { (years) }\end{array}$ & $6.4 \pm 5.6$ & - & \\
\hline Metformin dose (mg) & $1848 \pm 896$ & - & \\
\hline P-BI2 (pmol/L) & $309(149)$ & $326(129)$ & 0.368 (ns) \\
\hline P-magnesium (mmol/L) & 0.76 & 0.82 & $<0.001$ \\
\hline
\end{tabular}

Note: Data given are arithmetic mean $( \pm S D)$.

Abbreviations: $B I 2$, vitamin $B I 2$ (cobalamin); $B M I$, body mass index; $f$, fasting; F, female; $\mathrm{HbA}_{1 \mathrm{c}}$, glycated hemoglobin; $\mathrm{M}$, male; ns, not significant; P, plasma; SD, standard deviation; T2DM, type 2 diabetes mellitus.

Siemens). The coefficient of variation was $6 \%$. Normal reference interval in adults was $0.70-0.95 \mathrm{mmol} / \mathrm{L}$. Plasma B12 concentration was assayed by competitive immunoassay kit (Centaur XP, Siemens). The coefficient of variation was $15 \%$. Normal reference interval was $230-880 \mathrm{pmol} / \mathrm{L}$. Statistical results are given as arithmetic mean values with their standard deviations. A $p$ value $<0.05$ was considered statistically significant. Bivariate correlations are expressed as Pearson's correlation coefficient. Subgroup analysis on patients undergoing diabetes treatment was performed regarding gender and medication. The statistical software JMP 5.0 for PC (SAS Corporation, Cary, TX, USA) was used for all statistical calculations. The study was approved by the regional ethics review board at Uppsala University. All patients gave written informed consent prior to the study.

\section{Results}

There were differences between the two groups regarding age $(p<0.001)$, sagittal diameter $(p=0.004)$, glucose parameters $(p<0.001)$ and magnesium concentrations $(p<0.001)$. A longer diabetes duration was associated with lower magnesium concentrations $(p=0.039)$. The controls had a mean magnesium concentration of $0.82 \pm 0.06 \mathrm{mmol} / \mathrm{L}$, while in metformintreated T2DM patients it was $0.76 \pm 0.07 \mathrm{mmol} / \mathrm{L}(p<0.001$; Figure 1). Longer diabetes duration was also associated with a higher metformin dose $(p=0.014)$. There was no difference in renal function regarding plasma creatinine ( $\mathrm{p}$-creatinine) between the groups. A subgroup of 26 non-metformin-treated T2DM patients showed a normal magnesium concentration, compared to controls, that is, $0.81 \pm 0.06 \mathrm{mmol} / \mathrm{L}$. 


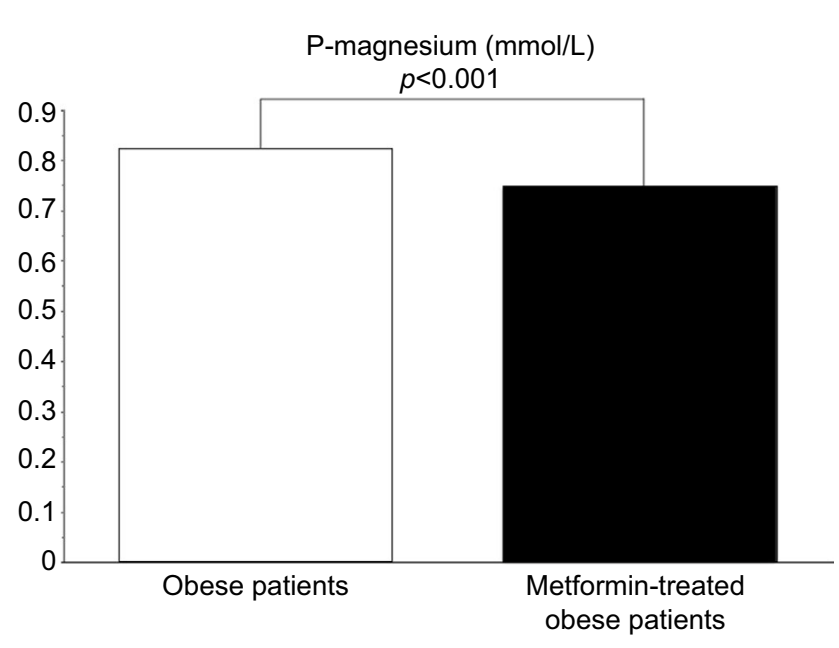

Figure I Difference in plasma magnesium (P-magnisium) $(\mathrm{mmol} / \mathrm{L})$ in absolute values between obese patients and metformin-treated T2DM obese patients. Abbreviation: P, plasma.

We found no statistical difference in B12 concentrations between the two groups $(326 \mathrm{pmol} / \mathrm{L}$ in controls vs 309 $\mathrm{pmol} / \mathrm{L}$ in T2DM; $p=0.368)$. B12 deficiency $(\leq 150 \mathrm{pmol} / \mathrm{L})$ was found in two controls and two T2DM patients $(1.9 \%$ vs $5 \%, p=0.294)$, and low B12 ( $\leq 200 \mathrm{pmol} / \mathrm{L})$ was found in five controls and four T2DM patients $(4.7 \%$ vs $10 \%, p=0.256)$.

A subgroup analysis of male and female metformintreated obese T2DM patients (19 vs 21 ) showed no difference in magnesium concentrations $(0.75 \pm 0.08$ vs $0.78 \pm 0.06$ $\mathrm{mmol} / \mathrm{L}, p=0.211)$, metformin dose (2092 \pm 745 vs $1652 \pm 943$ $\mathrm{mg}, p=0.117)$ and diabetes duration $(7.9 \pm 5.4$ vs $5.0 \pm 5.6$ years, $p=0.104)$.

\section{Discussion}

This study showed lower prevalence of B12 deficiency (5\%) than previous studies, with no statistically significant differences between the two groups of morbidly obese patients with and without T2DM. The association between metformin and B12 deficiency in this morbidly obese group with diabetes duration of 6.4 years and daily doses of $1848 \mathrm{mg}$ of metformin is possibly not so strong and could also be affected by other factors such as dairy intake. The control group was significantly younger than the metformin-treated group, and a possible influence of age on glucose metabolism is that it is known to deteriorate with higher age. This would have driven results toward the null hypothesis, thus possibly overestimating the differences observed, rather than underestimating them. The duration of diabetes was relatively short, and B12 deficiency increases not only with age but also with diabetes duration. Magnesium concentrations were significantly lower in the metformin-treated T2DM group compared to controls and non-metformin-treated T2DM patients, which possibly increases the risk for CVD, since hypomagnesemia is associated with CVD and death. Magnesium supplementation has also been shown to improve insulin resistance. Routine testing of B12 in metformin-treated obese patients should still be considered, as previous larger studies have shown a risk for B12 deficiency with metformin treatment, as well as testing of magnesium with consideration to substitution and to avoid low levels to fully benefit from metformin medication.

\section{Conclusion}

Metformin is widely used and is the first-line treatment for type 2 diabetes mellitus, but may cause lowered circulating B12 concentrations.

There are still few clinical recommendations/clinical guidelines regarding metformin treatment and detection of B12 deficiency.

We could not significantly separate the non-metformintreated group from metformin-treated group regarding B12 concentrations, as the prevalence of deficiency was $\sim 5 \%$ from the metformin-treated group.

Hypomagnesemia is associated with insulin resistance, inflammation and increased risk for CVD.

Magnesium was significantly lowered in metformin-treated group, and these patients could benefit from substitution.

\section{Acknowledgments}

Desire Nelson is acknowledged for keeping our database continuously updated.

\section{Disclosure}

The authors report no conflicts of interest in this work.

\section{References}

1. Holman RR, Paul SK, Bethel MA, Matthews DR, Neil HA. 10-year follow-up of intensive glucose control in type 2 diabetes. $N$ Engl J Med. 2008;359(15):1577-1589.

2. FogelmanY, Kitai E, Blumberg G, Golan-CohenA, Rapoport M, Carmeli E. Vitamin B12 screening in metformin-treated diabetics in primary care: were elderly patients less likely to be tested? Aging Clin Exp Res. 2016; 29(2):135-139.

3. Niafar M, Hai F, Porhomayon J, Nader ND. The role of metformin on vitamin B12 deficiency: a meta-analysis review. Intern Emerg Med. 2015; 10(1):93-102.

4. Aroda VR, Edelstein SL, Goldberg RB, et al. Long-term Metformin Use and Vitamin B12 Deficiency in the Diabetes Prevention Program Outcomes Study. J Clin Endocrinol Metab. 2016;101(4):1754-1761.

5. Peters KE, Chubb SA, Davis WA, Davis TM. The relationship between hypomagnesemia, metformin therapy and cardiovascular disease complicating type 2 diabetes: the Fremantle Diabetes Study. PloS One. 2013; 8(9):e74355.

6. McNair P, Christensen MS, Christiansen C, Madsbad S, Transbol I. Renal hypomagnesaemia in human diabetes mellitus: its relation to glucose homeostasis. Eur J Clin Invest. 1982;12(1):81-85.

7. Haglin L, Tornkvist B, Backman L. Prediction of all-cause mortality in a patient population with hypertension and type 2 DM by using traditional risk factors and serum-phosphate,-calcium and-magnesium. Acta Diabetol. 2007;44(3):138-143. 
Diabetes, Metabolic Syndrome and Obesity: Targets and Therapy is an international, peer-reviewed open-access journal committed to the rapid publication of the latest laboratory and clinical findings in the fields of diabetes, metabolic syndrome and obesity research. Original research, review, case reports, hypothesis formation, expert opinion and commentaries are all considered for publication. The manuscript management system is completely online and includes a very quick and fair peer-review system, which is all easy to use. Visit http://www.dovepress.com/testimonials.php to read real quotes from published authors.

Submit your manuscript here: https://www.dovepress.com/diabetes-metabolic-syndrome-and-obesity-targets-and-therapy-journal 